\title{
Why Nations Fail: The Origins of Power, Prosperity and Poverty
}

\author{
by Daron Acemoglu and James Robinson \\ New York: Crown 2012 \\ ISBN: 978-0-30771-921-8 \\ Hardcover, \$35, 544 pp. \\ Reviewed by Rick Szostak \\ Department of Economics, University of Alberta, Edmonton, Alberta
}

A physicist would be mocked for proclaiming that only one of the four subatomic forces really mattered. A chemist would be shunned for claiming that only covalent bonds should be studied. And a physiologist would be laughed at for arguing that only the digestive system determines an organism's wellbeing and development. But social scientists can still be applauded (as several Nobel Laureates do in the frontmatter of this book) for arguing that there is only one predominant cause of economic growth, and for actively dismissing all alternative explanations.

This is not to say that the authors' core arguments lack merit. Many social sciences have in recent decades appreciated the importance of institutions that give people confidence, freedom, and incentives to invest and exchange. And many scholars have noted that this type of economic institution is more likely to be found in societies with political institutions that are characterized also by freedoms and rights and pluralism. Readers of this journal may especially appreciate the argument in the early chapters that it was low population densities that encouraged "inclusive" political and economic institutions in what would become the United States, whereas higher population densities (coupled with the resources to be extracted from these populations) encouraged elitist "extractive" institutions across much of Latin America. (Population is largely ignored in other case studies.)

The determinism of these early chapters is cast away later in the book as the authors - laudably to be sure - appreciate the importance of historical contingency and path dependence (which they for some reason insist on calling institutional drift). But the recognition that small changes can have big effects imposes a heavy burden on historical analysis, for advocates of almost any theory can then potentially find some historical detail across a range of historical cases that supports their view of the world. These authors can be applauded for surveying widely across time and space, but they provide no insight into how they chose their cases. More importantly, one can read their discussion of European feudalism, the British Industrial Revolution, and a variety of other cases with no inkling whatsoever that historians have debated these historical cases - and the precise hypotheses favoured by these authors - for decades without achieving consensus.

The authors maintain that " $[$ ] $]$ he Industrial Revolution was manifested in every aspect of the English economy" (p. 197). And they heap praise on the British patent system. While I myself have doubted some claims that the Industrial Revolution was hardly felt beyond textiles and iron, even I must admit that there is weak evidence of widespread productivity advances. And the Industrial Revolution period is littered with inventors who could not enforce their patent rights. The authors' claims here seem to reflect their theory more than the evidence.

Admitting historical contingency must mean that the alternative explanations they took such pains to eliminate in chapter 2 sneak back in. Cultural explanations are panned in chapter 2, but it is admitted later that cultural attitudes might just affect which way a country turns in a time of transformation. Similar arguments could be made for any other causal variable. 
The authors do in their final chapter recognize that complex outcomes generally have complex causes, but argue that it is still useful to recognize patterns. This hardly seems a sufficient defence for dismissing entirely all the alternative explanations in chapter 2 and then simply ignoring alternative (or, indeed, simply complementary) explanations through most of the case studies.

The last chapter also contains a couple of pages devoted to dismissing feedback effects from economic growth to the institutions which the authors laud. They might have placed this material earlier, for the reader often has cause to wonder if the correlations between good institutions and impressive growth observed in previous chapters necessarily represent causation in the posited direction. One does not have to be a deconstructionist to appreciate some ambiguity in the text on this score. The authors appreciate that their much-loved Glorious Revolution in England depended on a broad-based coalition including large numbers of merchants and industrialists. But of course a certain degree of growth had to have happened in order for there to be a large number of influential merchants and industrialists. Later they make a general observation regarding "infrastructure, schools, and other public services essential for the development of inclusive institutions" (p. 451). Again, it would appear that economic development sets the stage for institutional change in the desired direction. And the political centralization that the authors see as essential to the right institutions will almost certainly depend on decent transport and communications, and these are associated with economic development.

The authors appreciate that transport improvements were an important element of the Industrial Revolution. But their list of facilitating institutions is seriously incomplete. Those transport developments depended critically on both easy incorporation and exercise of eminent domain. Corporations, as the authors note in their discussion of the robber barons, can be both instruments of economic growth and of a concentration of power inimical to growth. Eminent domain - the power of governments to expropriate land for public works-is not obviously an institution that serves the public rather than an elite (though in the case of Britain, at least it could be argued that eminent domain is more easily exercised in a polity where governments are trusted not to abuse power too much). One could argue that such institutions will only be put to good use in a good political environment, but such an argument would sail dangerously close to tautology. The authors seem rather to imply that there is a set of demonstrably inclusive institutions at work in successful countries. This seriously oversimplifies the nature of institutions.

The problem here, and elsewhere, is that the authors draw a strict dichotomy: There are countries with good political and economic institutions that grow, and countries with bad institutions that usually do not. There are, to be sure, feedback loops in both cases that reinforce good or bad outcomes, and the authors necessarily appreciate that these are imperfect. But they take great pains to doubt that there can be middle cases (they do admit that Egypt is somewhat less extractive than North Korea) — though casual empiricism suggests that a mix of socially beneficial and elite-serving institutions is not unusual. And if there are no middle cases, some sort of political revolution seems necessary to unleash sustainable economic growth, though the authors never quite admit that.

The authors laud the pluralistic banking sector that developed in the United States. But comparative studies suggest that the oligopolistic Canadian system delivered better interest rates on both deposits and loans, and was more stable. Just because an institution appears "inclusive" and occurs in a country that grew fast does not establish a causal relationship.

The authors boldly predict that economic growth in China will inevitably cease unless there is a transition toward a more pluralistic political structure. This may be true, but given the general failure of social science to either predict or explain China's phenomenal growth rates to date, a certain humility is called for. Coupled with the authors' dismissal of the possibility that economic growth at all encourages desirable political change, the posited future for China is bleak.

One key reason that China must fail involves technology. Since institutions are credited with being the sole source of sustainable economic growth, they must also be responsible for technological innovation. Why rates of innovation differ so much across developed nations is, then, a bit mysterious. And much of the research in technology policy (and economic development more generally) is apparently of little value.

There are some other anomalies. The authors, despite celebrating the Glorious Revolution, and appreciating that it built upon previous political institutions which could support plurality, are so enamoured of their popu- 
lation density argument that they refuse to accept the possibility that the United States (or Canada, Australia, and New Zealand) might have benefited from a British institutional inheritance. But when they come to explain Argentina's plight (Argentina is placed solidly in the bad category, while Brazil now is solidly in the good category), they appreciate that its Spanish institutional inheritance may have diverted it from the benefits of low population density.

In one of the earlier, more deterministic chapters they forcefully attribute the differing economic fortunes today of two Peruvian villages to their different treatment by the Spanish in the seventeenth century. And they do so despite recognizing that the prosperous village is connected by road to markets and the non-prosperous village is not (p. 18).

The policy implications of the authors' analysis are limited, given their stress on historical contingency. Greater attention to how yet other variables might interact to support inclusive institutions would have allowed more powerful advice. The authors are foreign aid skeptics, but recognize that it does some good. They might have stressed the benefits of aid for transport and education (and maybe healthcare and justice) for both generating growth directly and encouraging inclusive institutions. And they might have joined many development economists in seeking mechanisms for funneling aid past corrupt officials.

Despite my qualms about the book, I enjoyed reading it. It is stylishly written. The diverse case studies are packed with an entertaining amount of historical detail. The reader who is aware that alternative explanations of these various cases are simply dismissed or ignored - and especially the reader who doubts that good political institutions can foster good economic institutions, or that good economic institutions foster growth-can nevertheless benefit from reading this book. 